\title{
Sobrecrecimiento bacteriano en el intestino delgado: una causa de dolor abdominal crónico en niños
}

\author{
Small Intestinal Bacterial Overgrowth: a cause of chronic \\ abdominal pain in children
}

David Avelar-Rodríguez, ${ }^{1}$ Erick Manuel Toro-Monjaraz, ${ }^{2}$ Jaime Alfonso Ramírez-Mayans ${ }^{3}$

\section{ANTECEDENTES}

El sobrecrecimiento bacteriano en el intestino delgado (SBID) es causa de dolor abdominal crónico, diarrea, distensión abdominal y flatulencias en la población pediátrica. El uso de inhibidores de bomba de protones, algunas anomalías anatómicas y alteraciones en la motilidad gastrointestinal son factores de riesgo de SBID. El diagnóstico se establece con base en la prueba de hidrogeniones y de metano, o por medio del cultivo del aspirado duodenal/yeyunal. El tratamiento consiste en: rifaximina, dieta con restricción de oligosacáridos, disacáridos, monosacáridos y polioles fermentables (FODMAPs), y probióticos. ${ }^{1}$

\section{Fisiopatogenia y factores de riesgo}

La microbiota intestinal es un ecosistema dinámico y complejo; bajo condiciones fisiológicas, lacuenta bacteriana y la cantidad de bacterias anaerobias incrementan de manera caudal. La figura 1 muestra la composición bacteriana y el número de bacterias en cada porción anatómica. ${ }^{1,2}$

El aparato gastrointestinal tiene diferentes mecanismos para mantener la eubiosis de la microbiota, de tal manera que si alguno de estos se altera es posible que se desarrolle un SBID.

\footnotetext{
${ }^{1}$ Pasante del Servicio Social en investigación.

${ }^{2}$ Adscrito al servicio de Gastroenterología y a la Unidad de Motilidad y Fisiología Gastrointestinal.

${ }^{3}$ Jefe del Departamento de Gastroenterología.

Instituto Nacional de Pediatría.

Recibido: 17 de mayo 2018

Aceptado: 8 de febrero 2019

Correspondencia

David Avelar-Rodríguez davidavelar1@outlook.com

Este artículo debe citarse como Avelar-Rodríguez D, Toro-Monjaraz EM, Ramírez-Mayans JA. Sobrecrecimiento bacteriano en el intestino delgado: una causa de dolor abdominal crónico en niños. Acta Pediatr Mex. 2019;40(2):93-8.
} 


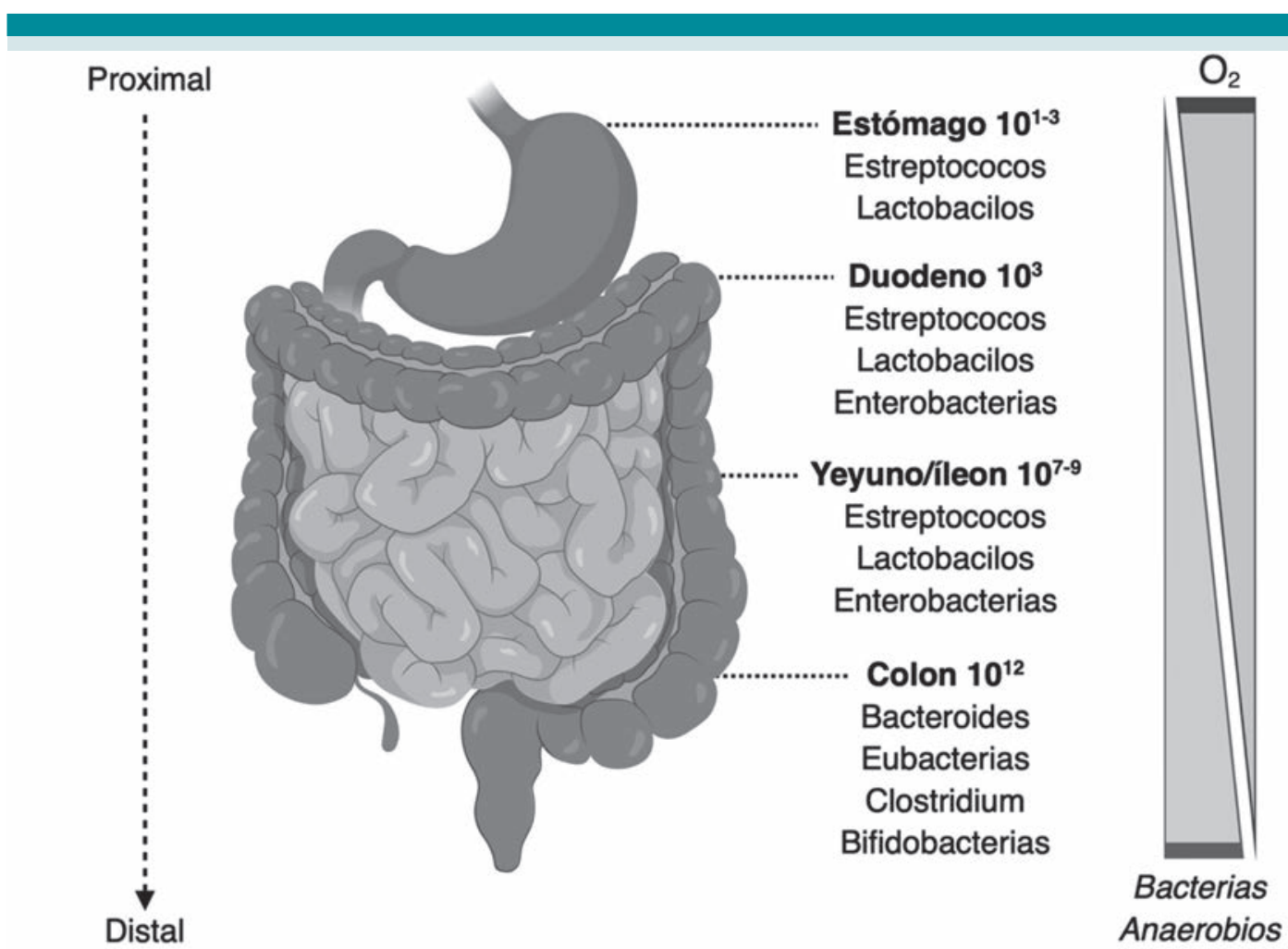

Figura 1. Aparato gastrointestinal con sus respectivas cuentas bacterianas y diferentes tipos de bacterias que habitan cada porción anatómica. Las cuentas bacterianas son expresadas en unidades formadoras de colonias (UFC)/mililitro (mL). Created with BioRender.

- Ácido gástrico. Éste es uno de los principales mecanismos que previenen la proliferación bacteriana en la parte alta del aparato gastrointestinal. La aclorhidria originada por el consumo de inhibidores de la bomba de protones se ha asociado con SBID; sin embargo, a la fecha muy pocos estudios han evaluado esta asociación en niños. En adultos, una revisión sistemática y un metaanálisis concluyeron que sí existe una asociación significativa y un riesgo elevado de SBID. Por lo tanto, el consumo prolongado e indiscriminado de inhibidores de la bomba de protones deb evitarse hasta no contar con más evidencia en la población pediátrica. ${ }^{1,3-5}$
- Motilidad intestinal. Ciertas alteraciones de la motilidad gastrointestinal pueden conducir al SBID, resultado de una alteración en el aclaramiento intestinal que, al mismo tiempo, ocasiona estasis fecal-bacteriana. Esto puede suceder en pacientes con fibrosis quística, estreñimiento o mielomeningocele.

- Anatomía gastrointestinal íntegra. Algunas alteraciones anatómicas congénitas, o adquiridas, pueden conducir al sobrecrecimiento bacteriano en el intestino delgado. En estos pacientes se afecta la motilidad y el aclaramiento gastrointestinal, lo que puede llevar a estasis bacteriana. Esto sucede en pacientes inter- 
venidos quirúrgicamente que produzcan el síndrome del asa ciega, con síndrome de intestino corto, con enfermedad de Crohn, que con fístulas o estenosis, o con resección de la válvula íleo-cecal. ${ }^{1}$

\section{Epidemiología}

Está reportado que, incluso, 35\% de los pacientes pediátricos asintomáticos tienen SBID. Collins y sus colaboradores encontraron una prevalencia de $91 \%$ en niños con dolor abdominal crónico, ${ }^{6}$ y Scarpellini y su grupo. reportaron una prevalencia de $65 \%$ en niños con síndrome de intestino irritable. ${ }^{7}$ En otro estudio de pacientes con dolor abdominal se encontró una prevalencia mayor de $60 \% .{ }^{8}$ En pacientes con fibrosis quística la prevalencia puede alcanzar porcentajes de $50 \%$. Por lo tanto, existe una variabilidad importante que depende de la población estudiada. ${ }^{1}$

\section{Cuadro clínico y tratamiento}

El cuadro clínico del SBID en niños es inespecífico y principalmente se sospecha en quienes tienen dolor abdominal crónico acompañado de distensión abdominal, eructos, flatulencias o cambios en el hábito intestinal. También se han descrito otros síntomas, como la desnutrición, pérdida de peso, detención del crecimiento, deficiencia de vitamina $B_{12}$, deficiencia de vitaminas liposolubles e hipoproteinemia. Los síntomas gastrointestinales son más comunes que los síntomas generales y, de estos, el dolor abdominal, las flatulencias y la distensión abdominal son los más frecuentes. Los síntomas gastrointestinales de SBID son parecidos a los del síndrome de intestino irritable; de hecho, se ha propuesto que esta enfermedad podría estar causada por el SBID. ${ }^{1}$

Por su naturaleza inespecífica, el SBID es un padecimiento a descartar, de manera que los síntomas serán la clave de la conducta médica hacia qué enfermedades descartar. Por ejemplo, lo primero a lo que se recurre en el Instituto $\mathrm{Na}$ cional de Pediatría es a descartar las causas más comunes: infecciosas; entre las más frecuentes están las parasitosis por Giardia lamblia y Blastocystis hominis. ${ }^{9}$ Figura 2

\section{Diagnóstico}

Existen dos maneras de diagnosticar el SBID: la directa y la indirecta. La primera es por medio del cultivo del aspirado duodenal/yeyunal, que es el patrón de referencia y el resultado es positivo cuando la cuenta bacteriana es $\geq 10^{3} \mathrm{UFC} / \mathrm{mL} .^{12}$ Sin embargo, su invasividad y su costo hacen que no se realice con frecuencia. La manera indirecta se lleva a cabo mediante los estudios de hidrógeno y metano exhalado, que son prácticos y fáciles de efectuar. Cuadro 1

En el intestino existen cuatro fuentes principales de gas: aire tragado, reacciones químicas, difusión de gas desde el torrente sanguíneo, y el metabolismo bacteriano. Estos gases son, principalmente: hidrógeno $\left(\mathrm{H}_{2}\right)$, dióxido de carbono $\left(\mathrm{CO}_{2}\right)$ y metano $\left(\mathrm{CH}_{4}\right)$. El hidrógeno y el metano los producen, exclusivamente, las bacterias intestinales por medio de la fermentación de carbohidratos; Por esto, al administrar los sustratos (glucosa [75 g] o lactulosa [0.5 g/kg máximo $10 \mathrm{~g}]$ ), esto resultara en una producción de hidrógeno y/o metano, los cuales se absorben a la circulación sistémica para después ser exhalados por los pulmones y detectados por medio de sensores electroquímicos específicos para hidrógeno o metano. ${ }^{1,12}$

Cuadro 1. Especificad, sensibilidad, valor predictivo positivo (VPP) y valor predictivo negativo (VPN) de la prueba de hidrogeniones con lactulosa y glucosa. ${ }^{1,11,12}$

\begin{tabular}{|l|c|c|c|c|} 
& Sensibilidad & Especificidad & VPP & VPN \\
\hline Glucosa & $62.5 \%$ & $81.8 \%$ & $80.0 \%$ & $65.5 \%$ \\
\hline Lactulosa & $52.4 \%$ & $85.7 \%$ & $61.5 \%$ & $53.6 \%$ \\
\hline
\end{tabular}




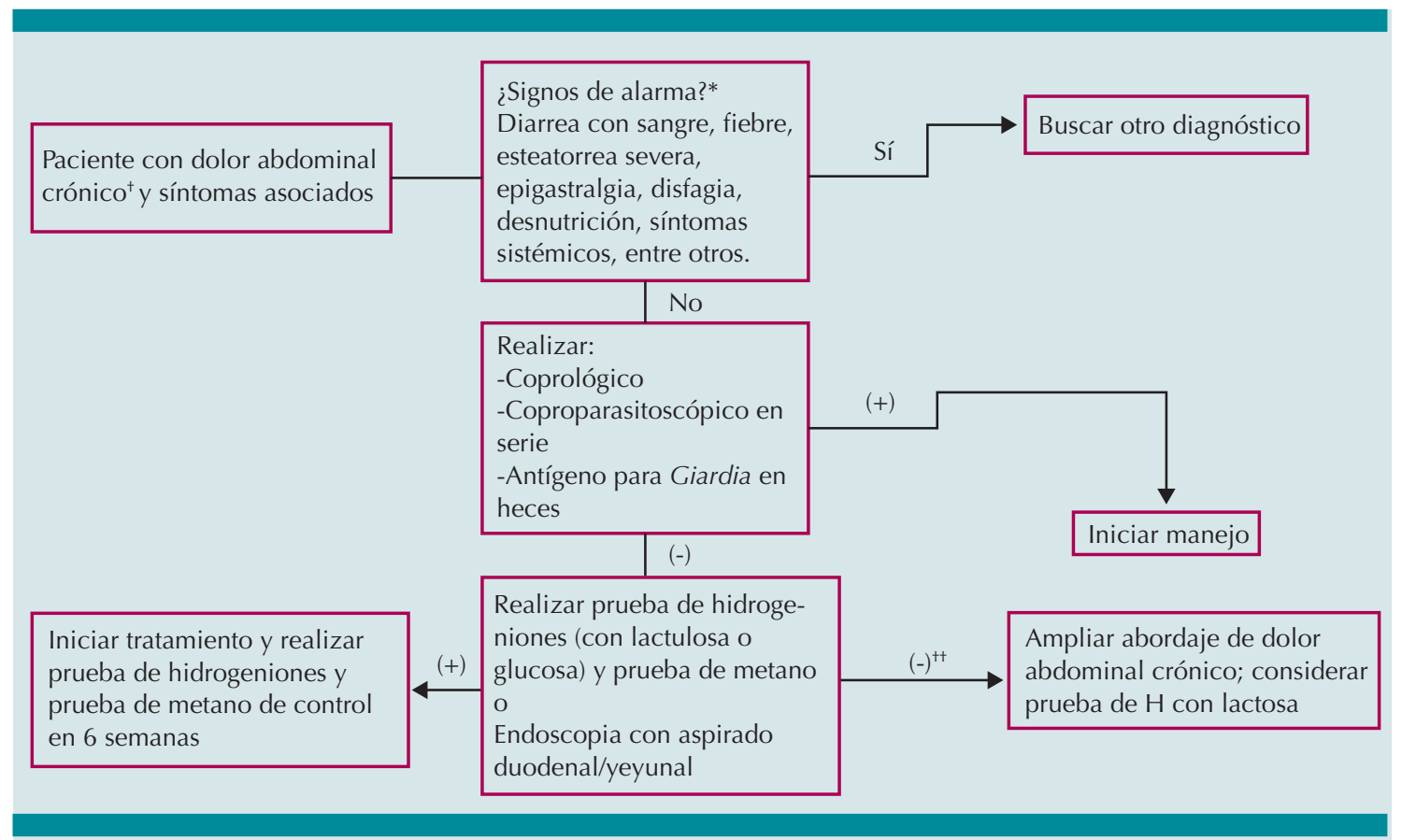

Figura 2. Diagrama de flujo para el diagnóstico y tratamiento del paciente con sospecha de sobrecrecimiento bacteriano en el intestino delgado. + Dolor abdominal episódico o continuo que ha durado, al menos, 2 meses; ${ }^{10}$ *también indica signos y síntomas que podrían estar causados por otras enfermedades. †† En caso de ser negativo y tener una alta sospecha clínica se podrá iniciar el tratamiento empírico considerando el bajo VPN.

\section{Tratamiento}

El tratamiento del SBID puede implicar tres aspectos terapéuticos: 1) disminuir o erradicar el exceso de bacterias; 2) restringir los sustratos bacterianos por medio de la dieta; y 3) reponer y modular la microbiota intestinal.

- Para el primer punto, el antibiótico de elección es la rifaximina, que cuenta con la propiedad de ser intraluminal (se excreta más de $95 \%$ en las heces de forma intacta), y tiene cobertura para bacterias gram-positivas, gram-negativas, aerobias y anaerobias. Además, recientemente se demostró su efecto modulador en la microbiota gastrointestinal. Está indicada a dosis de 30 mg/kg/día durante 7-10 días. ${ }^{13,14,15}$
Para restringir los sustratos bacterianos por medio de la dieta lo indicado son los oligosacáridos, disacáridos, monosacáridos y polioles fermentables.

- Esta dieta restringe: lácteos, jugos, frutas dulces, leguminosas, cereales y algunos vegetales. Como es una dieta sumamente estricta solo debe prescribirse por un tiempo limitado pues se restringen muchos de los nutrimentos esenciales para el crecimiento y desarrollo. Se recomienda indicarla durante seis semanas. Para consultar esta dieta con mayor detalle visite http://fodmapliving.com/ wp-content/uploads/2013/02/StanfordUniversity-Low-FODMAP-Diet-Handout. pdf ${ }^{16,17}$ En la experiencia del servicio de 
Gastroenterología del INP, indicar la dieta junto con el antibiótico disminuye los síntomas en los niños. Si bien aún falta evidencia que aclare este punto, el único ensayo clínico efectuado en niños demuestra que es efectivo en el tratamiento del dolor abdominal crónico.

- Los probióticos modulan y reponen la microbiota intestinal. Éste, es un punto importante porque al indicar cualquier antibiótico, sobre todo si es intraluminal, la microbiota intestinal es "barrida", por lo que reponerla es de gran trascendencia. Además, tiene efectos moduladores que disminuyen el dolor abdominal y contribuyen a erradicar las bacterias causantes del SBID. Si bien los probióticos pueden ser de utilidad, aún no puede determinarse qué cepas son las más efectivas; la única revisión sistemática disponible hasta el momento muestra que, en general, los probióticos ayudan a tratar el SBID, disminuyen la concentración de hidrógeno y disminuyen el dolor abdominal. ${ }^{17}$

\section{CONCLUSIONES}

- Con frecuencia, los pacientes con SBID tienen dolor abdominal, diarrea, distensión abdominal, flatulencias y síntomas tipo síndrome de intestino irritable.

- El SBID de niños es más frecuente de lo que se piensa; por lo tanto, debe sospecharse en pacientes con dolor abdominal crónico.

- Los pacientes deberán tratarse considerando los tres puntos señalados para conseguir una respuesta óptima.

\section{REFERENCIAS}

1. Sieczkowska A, et al. Small bowel bacterial overgrowth in children. J Pediatr Gastroenterol Nutr. 2016;62(2):196-207. doi: 10.1097/MPG.0000000000000920
2. Bohm M, et al. Diagnosis and management of small intestinal bacterial overgrowth. Nutr Clin Pract. 2013;28(3):28999. doi: $10.1177 / 0884533613485882$

3. Lo WK, et al. Proton pump inhibitor use and the risk of small intestinal bacterial overgrowth: a meta-analysis. Clin Gastroenterol Hepatol. 2013;11(5):483-90. doi: 10.1016/j. cgh.2012.12.011.

4. Cares K, et al. Short article: Risk of small intestinal bacterial overgrowth with chronic use of proton pump inhibitors in children. Eur J Gastroenterol Hepatol. 2017;29(4):396-399. doi: 10.1097/MEG.0000000000000815

5. Su T, et al. Meta-analysis: proton pump inhibitors moderately increase the risk of small intestinal bacterial overgrowth. J Gastroenterol. 2018 Jan;53(1):27-36. doi: 10.1007/s00535-017-1371-9

6. Collins BS, et al. Chronic abdominal pain in children is associated with high prevalence of abnormal microbial fermentation. Dig Dis Sci. 2010;55(1):124-30. DOI: 10.1007/ s10620-009-1026-7.

7. Scarpellini $E$, et al. Prevalence of small intestinal bacterial overgrowth in children with irritable bowel syndrome: a case-control study. J Pediatr. 2009 Sep;155(3):416-20. doi: 10.1016/j.jpeds.2009.03.033.

8. Siniewicz-Luzeńczyk $\mathrm{K}$, et al. Small intestinal bacterial overgrowth syndrome in children. Prz Gastroenterol. 2015;10(1):28-32. doi: 10.5114/pg.2014.47494

9. Toro Monjaraz EM, et al. Blastocystis hominis and chronic abdominal pain in children: Is there an association between them? J Trop Pediatr. 2018;64(4):279-83. doi: 10.1093/ tropej/fmx060.

10. Hyams JS, et al. Functional Disorders: Children and Adolescents. Gastroenterology. 2016 Feb 15. doi: 10.1053/j. gastro.2016.02.015.

11. Gasbarrini A, et al. 1st Rome H2-Breath Testing Consensus Conference Working Group. Methodology and indications of $\mathrm{H} 2$-breath testing in gastrointestinal diseases: the Rome Consensus Conference. Aliment Pharmacol Ther. 2009;29 Suppl 1:1-49.

12. Rezaie A, et al. Hydrogen and Methane-Based Breath Testing in Gastrointestinal Disorders: The North American Consensus. Am J Gastroenterol. 2017;112(5):775-84. doi: 10.1038/ajg.2017.46.

13. Scarpellini $E$, et al. Rifaximin treatment for small intestinal bacterial overgrowth in children with irritable bowel syndrome. Eur Rev Med Pharmacol Sci. 2013;17(10):1314-20.

14. Pistiki $A$, et al. In vitro activity of rifaximin against isolates from patients with small intestinal bacterial overgrowth. Int J Antimicrob Agents. 2014;43(3):236-41. doi: 10.1016/j. ijantimicag.2013.12.008.

15. Soldi $S$, et al. Modulation of the gut microbiota composition by rifaximin in non-constipated irritable bowel syndrome 
patients: a molecular approach. Clin Exp Gastroenterol. 2015;8:309-25. doi: 10.2147/CEG.S89999.

16. Chumpitazi BP, et al. Randomised clinical trial: gut microbiome biomarkers are associated with clinical response to a low FODMAP diet in children with the irritable bowel syndrome. Aliment Pharmacol Ther. 2015;42(4):418-27. doi: 10.1111/apt.13286.
17. lacovou M. Adapting the low FODMAP diet to special populations: infants and children. J Gastroenterol Hepatol. 2017 Mar;32 Suppl 1:43-45. doi: 10.1111/jgh.13696.

18. Zhong $C$, et al. Probiotics for preventing and treating small intestinal bacterial overgrowth: A meta-analysis and systematic review of current evidence. J Clin Gastroenterol. 2017 Apr;51(4):300-11. https://doi.org/10.1097/ MCG. 0000000000000814 